\title{
Infection of zebrafish embryos with live fluorescent Streptococcus pneumoniae as a real-time pneumococcal meningitis model
}

Kin Ki Jim ${ }^{1,2}$, JooYeon Engelen-Lee², Astrid M. van der Sar ${ }^{1}$, Wilbert Bitter ${ }^{1}$, Matthijs C. Brouwer², Arie van der Ende ${ }^{3,4}$, Jan-Willem Veening ${ }^{5}$, Diederik van de Beek ${ }^{2+}$ and Christina M. J. E. Vandenbroucke-Grauls ${ }^{1,6^{*}+}$

\begin{abstract}
Background: Streptococcus pneumoniae is one of the most important causes of bacterial meningitis, an infection where unfavourable outcome is driven by bacterial and host-derived toxins. In this study, we developed and characterized a pneumococcal meningitis model in zebrafish embryos that allows for real-time investigation of early host-microbe interaction.

Methods: Zebrafish embryos were infected in the caudal vein or hindbrain ventricle with green fluorescent

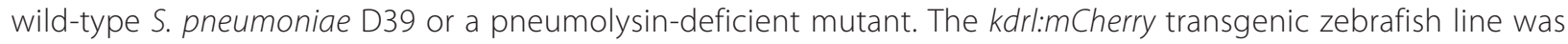
used to visualize the blood vessels, whereas phagocytic cells were visualized by staining with far red anti-L-plastin or in mpx:GFP/mpeg 1:mCherry zebrafish, that have green fluorescent neutrophils and red fluorescent macrophages. Imaging was performed by fluorescence confocal and time-lapse microscopy.

Results: After infection by caudal vein, we saw focal clogging of the pneumococci in the blood vessels and migration of bacteria through the blood-brain barrier into the subarachnoid space and brain tissue. Infection with pneumolysindeficient S. pneumoniae in the hindbrain ventricle showed attenuated growth and migration through the brain as compared to the wild-type strain. Time-lapse and confocal imaging revealed that the initial innate immune response to S. pneumoniae in the subarachnoid space mainly consisted of neutrophils and that pneumolysin-mediated cytolytic activity caused a marked reduction of phagocytes.

Conclusions: This new meningitis model permits detailed analysis and visualization of host-microbe interaction in pneumococcal meningitis in real time and is a very promising tool to further our insights in the pathogenesis of pneumococcal meningitis.
\end{abstract}

Keywords: Pneumococcal meningitis, Pneumolysin, Live cell imaging, Streptococcus pneumoniae, Zebrafish, Host-microbe interaction

\section{Background}

Streptococcus pneumoniae is a major cause of serious infections such as sepsis, pneumonia and meningitis. Despite advances in pneumococcal vaccines and effective antimicrobial therapy, the disease burden of invasive pneumococcal disease remains high, especially in

\footnotetext{
*Correspondence: vandenbrouckegrauls@vumc.nl

${ }^{\dagger}$ Equal contributors

'Department of Medical Microbiology and Infection Control, VU University Medical Center, De Boelelaan 1108, $1081 \mathrm{HZ}$ Amsterdam, The Netherlands ${ }^{6}$ Department of Medical Microbiology and Infection Control, VU University Medical Center, P.O. Box 7057, 1007 MB Amsterdam, The Netherlands
} Full list of author information is available at the end of the article resource-poor countries [1, 2]. Pneumococcal meningitis is a severe form of bacterial meningitis in children and adults [2-5]. The mortality rate ranges from 16 to $37 \%$ in developed countries and up to $51 \%$ in resource-poor areas $[1,4]$. Approximately 30 to $52 \%$ of patients surviving pneumococcal meningitis have disabling long-term neurological sequelae, such as focal neurologic deficits and cognitive slowness [5-7].

Susceptibility to and severity of pneumococcal meningitis are determined by host as well as pathogen characteristics $[8,9]$. Immune status and disruption of the natural barriers of the brain are well-recognized factors influencing host 
susceptibility [1]. In recent years, the host's genetic make-up has been increasingly recognized to determine susceptibility, for instance, due to genetic variation in innate immune receptors (Toll-like receptor 4), Fc gamma (Fc- $\gamma$ ) receptors and complement system [1, 8]. Also, the make-up of the pathogen is important; pneumococci harbour an array of virulence factors $[10,11]$. The most important of these is the polysaccharide capsule with over 90 distinct serotypes identified. Carriage rates and invasiveness differ for the different serotypes [12]. The capsule protects the bacteria from opsonophagocytosis and inhibits complement activation [13]. Other important virulence factors include the cytolytic toxin pneumolysin and several cell-surface proteins, such as pneumococcal surface protein A (PspA) [10, 11]. The relationship between the bacterium and the host drives pneumococcal genome variation; less than $50 \%$ of pneumococcal genes is present in all strains (the core genome) exemplifying this genome variability [14]. Both the presence and absence of genetic regions but also single nucleotide variations in the core genome can increase the pathogen's capacity to cause disease and influence disease severity $[9,15]$.

To study pneumococcal virulence, different experimental murine models have been developed [16-18]. Limitations of these murine models include ethical issues, high costs and time needed for experiments; these limitations render mice not suitable for large-scale screening [17]. The zebrafish (Danio rerio) has emerged as a powerful vertebrate model to study infectious diseases caused by human pathogens or their related animal pathogens [19-22]. Zebrafish are teleost fish with an innate and adaptive immune system similar to the human immune system [22-24]. The innate immune system is already active at very early stages during zebrafish embryo development, whereas the adaptive immune system is active $4-6$ weeks post fertilization [23]. Another advantage of this model is the unique ability to study host-pathogen interaction in real time because of the transparency of zebrafish embryos and the wide range of available fluorescent tools [22, 25]. Other advantages include high fecundity of the zebrafish, external development of the embryo and availability of gene-editing tools and tools to manipulate gene expression [26]. Additionally, this model can be used for mediumthroughput screening to identify bacterial mutants with altered virulence or medium-throughput screening of pharmacological compounds [27, 28]. Recently, this model has been adapted to visualize and study mycobacterial meningitis - a central nervous system infectious disease [29]. Moreover, it has been shown that zebrafish embryos as well as adult zebrafish are susceptible to pneumococcal infection and develop meningitis [30, 31].

The aim of our study was to develop a zebrafish embryo infection model of pneumococcal meningitis that allows for real-time analysis of the host-pathogen interaction. To this end, we infected zebrafish embryos with a highly green fluorescent strain of pneumococcus that is still fully virulent [32]. Visualization of the infection was further improved by using a transgenic fish line ( $k d r l: m C h e r r y)$ that has red fluorescent blood vessels, in combination with fluorescent far red staining of phagocytic cells with fluorescently labelled anti-L-plastin. Phagocyte dynamics were studied in more detail in a double-labelled mpx:GFP/ mpeg1:mCherry zebrafish line with green fluorescent neutrophils and red fluorescent macrophages.

\section{Methods}

\section{Bacterial strains and growth conditions}

S. pneumoniae serotype 2 D39 wild-type strain and a pneumolysin-deficient D39 mutant were used [33, 34]. All pneumococcal strains were grown overnight on Columbia agar plates supplemented with $5 \%$ defibrinated sheep blood at $37{ }^{\circ} \mathrm{C}$ in a humidified atmosphere with $5 \% \mathrm{CO}_{2}$. Green fluorescent S. pneumoniae D39 mutant strains were generated by fusing superfolder green fluorescent protein (sfGFP) to the histone-like protein HlpA as described by Kjos et al. [32]. Pneumococcal strains labelled with HlpA-GFP are fully virulent and have been used for in vitro and in vivo imaging [32]. Transformants were selected on plates containing $4.5 \mu \mathrm{g} / \mathrm{ml}$ chloramphenicol. Bacteria were collected from an overnight culture and suspended in Todd Hewitt broth supplemented with $0.5 \%$ yeast extract (Difco, Becton Dickinson) and grown to mid $\log$ phase at $37^{\circ} \mathrm{C}$. Cells were harvested by centrifugation $(6000 \mathrm{rpm}, 10 \mathrm{~min})$, washed with sterile phosphate-buffered saline (PBS), suspended in PBS with $20 \%$ glycerol to obtain the desired concentrations and stored at $-80{ }^{\circ} \mathrm{C}$. Before injection, bacteria were suspended in sterile $0.5 \%(w / v)$ phenol red solution (Sigma-Aldrich; P0290) to aid visualization of the injection process. The number of colony-forming units (CFU) per injection was determined by quantitative plating of the injection volume.

\section{Zebrafish husbandry, embryo care and injection procedure}

Adult $T g(k d r l: m C h e r r y)^{s 896}$ wild-type zebrafish expressing red fluorescence in the blood vessel endothelial cells, adult double-labelled $\operatorname{Tg}(m p x: G F P)^{i 114} / \operatorname{Tg}$ (mpeg1:mCherry $)^{g l 23}$ expressing green neutrophils and red macrophages, and the transparent adult casper mutant zebrafish (mit$f a^{w 2 / w 2} ;$ roy ${ }^{a 9 / a 9}$ ) were maintained at $26{ }^{\circ} \mathrm{C}$ in aerated 5-L tanks with a 10/14 h dark/light cycle [35-38]. Zebrafish embryos were collected within the first hours post fertilization (hpf) and kept at $28{ }^{\circ} \mathrm{C}$ in E3 medium $(5.0 \mathrm{mM} \mathrm{NaCl}, 0.17 \mathrm{mM} \mathrm{KCl}, 0.33 \mathrm{mM}$ $\mathrm{CaCl} \cdot 2 \mathrm{H}_{2} \mathrm{O}, 0.33 \mathrm{mM} \quad \mathrm{MgCl}_{2} \cdot 7 \mathrm{H}_{2} \mathrm{O}$ ) supplemented with $0.3 \mathrm{mg} / \mathrm{L}$ methylene blue. Embryos collected from $\operatorname{Tg}(k d r l \text { :mcherry })^{s 896}$ wild-type zebrafish and 
$\operatorname{Tg}(m p x: G F P)^{i 114} / T g$ (mpeg1:mCherry $)^{g l 23}$ wild-type zebrafish were additionally treated with $0.003 \%(v / v) 1$ phenyl 2-thiourea (PTU) to inhibit the formation of melanocytes [39]. Prior to injection and live imaging, 2 and 4 days post fertilization (dpf) embryos were mechanically dechorionated if necessary and anaesthetised in $0.02 \%(w / v)$ buffered 3-aminobenzoic acid methyl ester (pH 7.0) (Tricaine; Sigma-Aldrich, A5040). The zebrafish embryos were individually infected by microinjection with $1 \mathrm{nl}$ of $S$. pneumoniae either in the hindbrain ventricle or in the caudal vein as described elsewhere [40]. All procedures involving zebrafish embryos were according to local animal welfare regulations.

\section{Survival experiments in infected zebrafish embryos}

After infection, casper mutant zebrafish embryos were kept in 6-well plates at $28{ }^{\circ} \mathrm{C}$ with 20 individually injected embryos in each group per well. The mortality rate was determined by monitoring live and dead embryos at fixed time points between 12 and 120 hours post injection (hpi). All experiments were performed in triplicates.

\section{Fluorescence imaging of zebrafish embryos}

Screening and imaging of HlpA-GFP S. pneumoniae-infected and non-infected zebrafish embryos were performed with a Leica MZ16FA fluorescence microscope with a Leica DFC420C camera attached. Non-infected control zebrafish embryos and embryos with visible fluorescent bacteria after infection were selected at previously determined time points and fixated overnight in $4 \%$ paraformaldehyde in PBS. Subsequently, the embryos were stored in $100 \%$ methanol at $-20^{\circ} \mathrm{C}$ for maximal of 2 month or until further use. Confocal images were generated with a Leica TCS SP8 Confocal Microscope. For optimal imaging, embryos were embedded in $1.5 \%$ low-melting-point agarose dissolved in PBS in an open uncoated 8-well microscopy $\mu$-Slide (http://ibidi.com). Leica Application Suite X software was used to process the confocal images, specifically for brightness/contrast enhancements as well as for creating merged images.

\section{Time-lapse fluorescence imaging of zebrafish embryos}

Time-lapse bright-field and fluorescence images were acquired with a Zeiss Axio Zoom V16 stereo microscope. Double-labelled $\operatorname{Tg}(m p x: G F P)^{i 114} / \operatorname{Tg}(m p e g 1: m C h e r r y)^{g l 23}$ zebrafish embryos were imaged 15 min after injection in the hindbrain ventricle with wild-type $S$. pneumoniae. Images were obtained at $1 \mathrm{~min}$ intervals for $2.5 \mathrm{~h}$. Embryos were embedded in $1.5 \%$ low-melting-point agarose dissolved in egg water $(60 \mu \mathrm{g} / \mathrm{mL}$ sea salts (Sigma-Aldrich; S9883) in MiliQ) in a 35-mm Petri dish immediately after injection and kept at $28{ }^{\circ} \mathrm{C}$ using a custom-made temperature-controlled beaker with a glass bottom and heated lid to avoid condensation. Zeiss Zen Pro, Photoshop CS6 and ImageJ software were used to process the timelapse images, specifically for brightness/contrast enhancements as well as for stitching images.

\section{Immunohistochemical staining}

Phagocytic cells of zebrafish embryos were stained with an anti-L-plastin staining $[41,42]$. The anti-L-plastin was a kind gift from P. Morgan (Bristol University, UK). Briefly, stored, frozen embryos were rehydrated and rinsed with PBTx (1 \% Triton X-100 in PBS), permeated in $0.24 \%$ trypsin in PBS and blocked for $3 \mathrm{~h}$ in block buffer (10\% normal goat serum (NGS) in $1 \%$ PBTx) to minimize non-specific binding of the antibodies. Incubation with anti-L-plastin (1:500 $v / v$ dilution) in antibody buffer (1\% $(v / v)$ NGS and $1 \%(w / v)$ bovine serum albumin (BSA) in $1 \%$ PBTx was done overnight at room temperature on a seesaw rocker. After washing with PBTx and incubation for $1 \mathrm{~h}$ in the block buffer, embryos were incubated with Alexa 647 goat-anti-rabbit secondary antibody (Life technologies, 1:400 dilution) overnight at $4{ }^{\circ} \mathrm{C}$.

\section{Histopathological analysis}

For histopathological analysis, 2 and 4 dpf casper mutant zebrafish embryos were infected with wild-type $S$. pneumoniae D39 via caudal vein or hindbrain injection. The zebrafish embryos were anaesthetised with tricaine, fixated in $4 \%$ paraformaldehyde in PBS, embedded in paraffin and sectioned sagittally in $4 \mu \mathrm{m}$ thickness. The sections were mounted on StarFrost microscope slides, and Nissl staining was used. The stained slides were scanned with a Menari D-SIGHT fluo scanner (Florence, Italy) at $\times 100$ magnification with oil immersion for histopathological evaluation.

\section{Graphs and statistical analysis}

Statistics and graphs were generated with GraphPad Prism 6.0. Survival data were analysed with the log rank (Mantel-Cox) test. Results were considered statistically significant at $p$ values of $<0.05 \%$.

\section{Results}

Hindbrain ventricle and caudal vein injection with $S$. pneumoniae cause a fulminant, dose-dependent infection in zebrafish embryos

\section{Hindbrain ventricle infection}

To study whether S. pneumoniae can cause meningitis in zebrafish embryos, we directly injected bacteria in the hindbrain ventricle (Fig. 1a; red arrow). Infection was dose-dependent in $2 \mathrm{dpf}$ embryos: higher doses of bacteria resulted in earlier onset of disease and higher mortality rate. The survival of combined experiments at 120 hpi was 52 of $60(88 \%)$ embryos injected with 


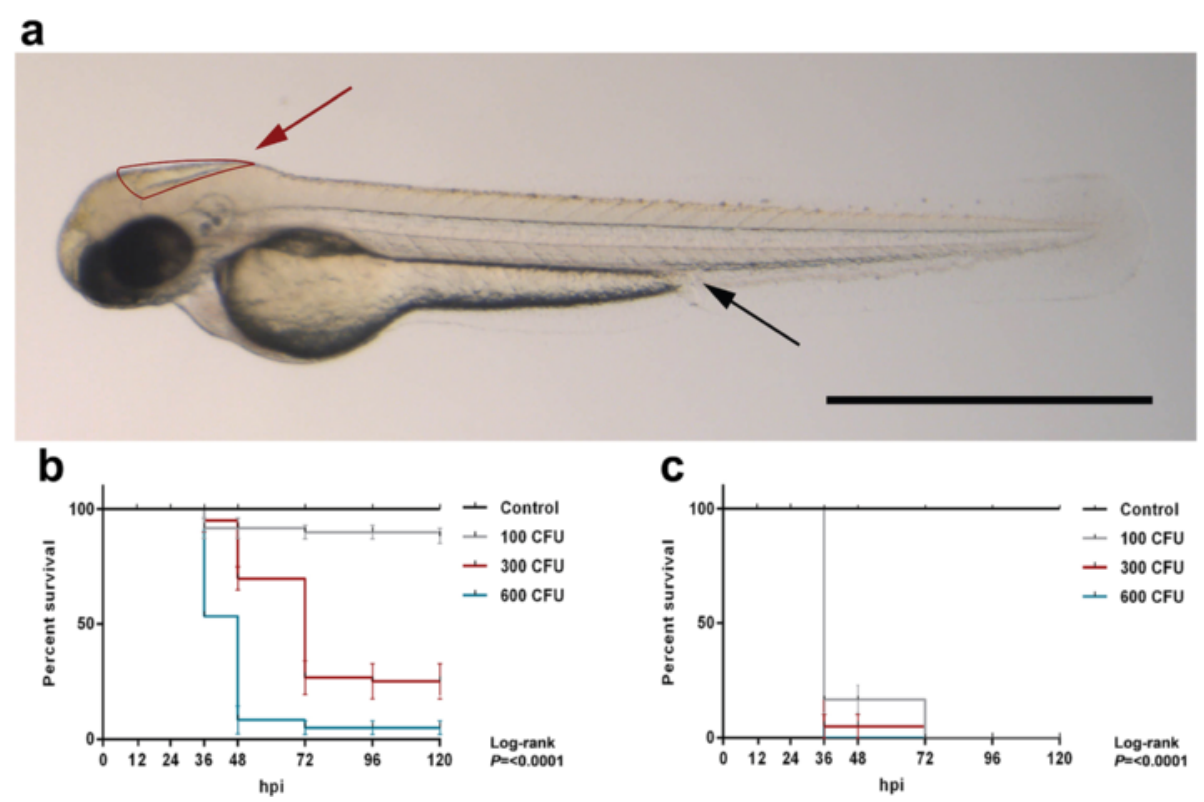

Fig. 1 Survival curves of 2 days post-fertilization embryos injected through different routes with wild-type Streptococcus pneumoniae D39. a Casper zebrafish embryo at 2 days post - fertilization. Red arrow indicates the hindbrain ventricle infection route, and black arrow indicates the caudal vein infection route. Scale bar, $500 \mu \mathrm{m}$. b, c Injection in the $\mathbf{b}$ hindbrain ventricle (HBV) or c caudal vein with indicated doses. Hpi hours post injection, CFU colony-forming units. The data represent the mean \pm SEM of three individual experiments with 20 embryos in each group

100 CFU, 15 of 60 (25\%) embryos injected with 300 and 3 of 60 (5\%) embryos injected with 600 CFU (Fig. 2b).

To visualize the localization of bacterial infiltrates, we used the green fluorescent HlpA-GFP S. pneumoniae D39 strain. After injection in the hindbrain ventricle, the infection remained mainly confined to the central nervous system (Fig. 2a). When smaller infection doses were used ( 300 CFU), death was delayed and sometimes preceded by bacteraemia (Additional file 1: Figure S1). To study the dynamics between $S$. pneumoniae and the innate immune system in more detail, phagocytes of infected zebrafish embryos were stained with anti-L-plastin and followed over time. Pneumococci injected in the hindbrain ventricle grew rapidly in number and migrated throughout the subarachnoid space, delineating the ventricular contours. In the early phase of infection, phagocytes migrated in large numbers to the site of infection. As the infection continued to progress, the number of phagocytes in the
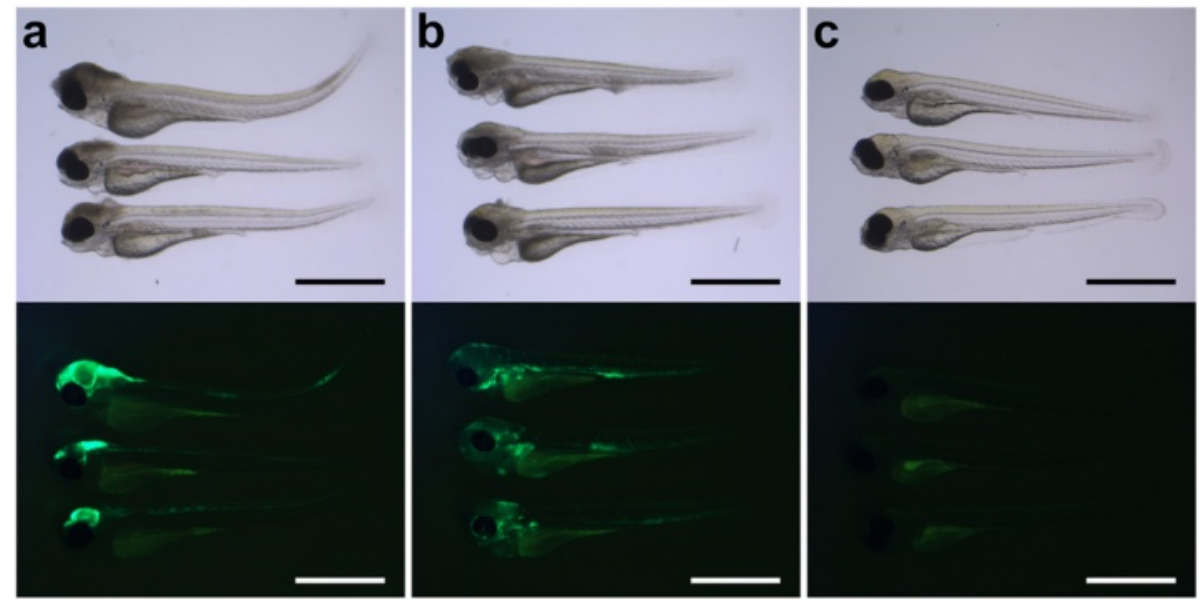

Fig. 2 Bright-field images with corresponding fluorescent images of 2 day-post-fertilization zebrafish embryos infected by different routes. a, $\mathbf{b}$ Lateral view of zebrafish embryos injected in the $\mathbf{a}$ hindbrain ventricle or $\mathbf{b}$ in the caudal vein. $\mathbf{c}$ Non-injected control embryos. Please note that there is usually some background fluorescence observed in the yolk. All embryos were infected with 400 CFU of Streptococcus pneumoniae D39 (HlpA-GFP) and imaged at $48 \mathrm{~h}$ post injection. Scale bars, $500 \mu \mathrm{m}$ 
hindbrain reduced over time in the presence of increasing numbers of bacteria (Fig. 3a), possibly due to the cytotoxic activity of pneumolysin. Histopathological analysis showed a similar pattern of increasing amount of bacteria in the subarachnoid space over time. In addition, bacteria were able to infiltrate the brain parenchyma (Fig. 4).

\section{Systemic infection}

We injected 2 dpf zebrafish embryos with HlpA-GFP $S$. pneumoniae in the caudal vein (Fig. 1a; black arrow). Injection of increasing doses of pneumococci in the caudal vein resulted in a dose-dependent infection. The mean survival percentages of the combined experiments were $0 \%$ in $100 \mathrm{CFU} / \mathrm{embryo}, 300 \mathrm{CFU} / \mathrm{embryo}$ and $600 \mathrm{CFU} /$ embryo (Fig. 1c), clearly indicating that compared to hindbrain ventricle injection, injection in the caudal vein was associated with a more rapid disease progression (Fig. 1b, c). Bacterial infiltrates were observed throughout the whole body of the zebrafish and also in the central nervous system (Fig. 2b). Injection in the caudal vein of $T g(k d r l: m \text { Cherry })^{s 896}$ zebrafish embryos allowed for detailed examination of the relation between the bacteria and the cerebrovascular system and showed pneumococci migrating out of the blood vessels into the central nervous system (Fig. 5). Histopathological analysis showed bacteria in the brain parenchyma as early as $12 \mathrm{hpi}$ (Fig. 6).

\section{Pneumolysin-deficient mutant is attenuated in the zebrafish embryo meningitis model}

To study whether a pneumolysin-deficient mutant pneumococcal strain (D39 $\Delta p l y)$ was attenuated as compared to the wild-type strain in our zebrafish embryo

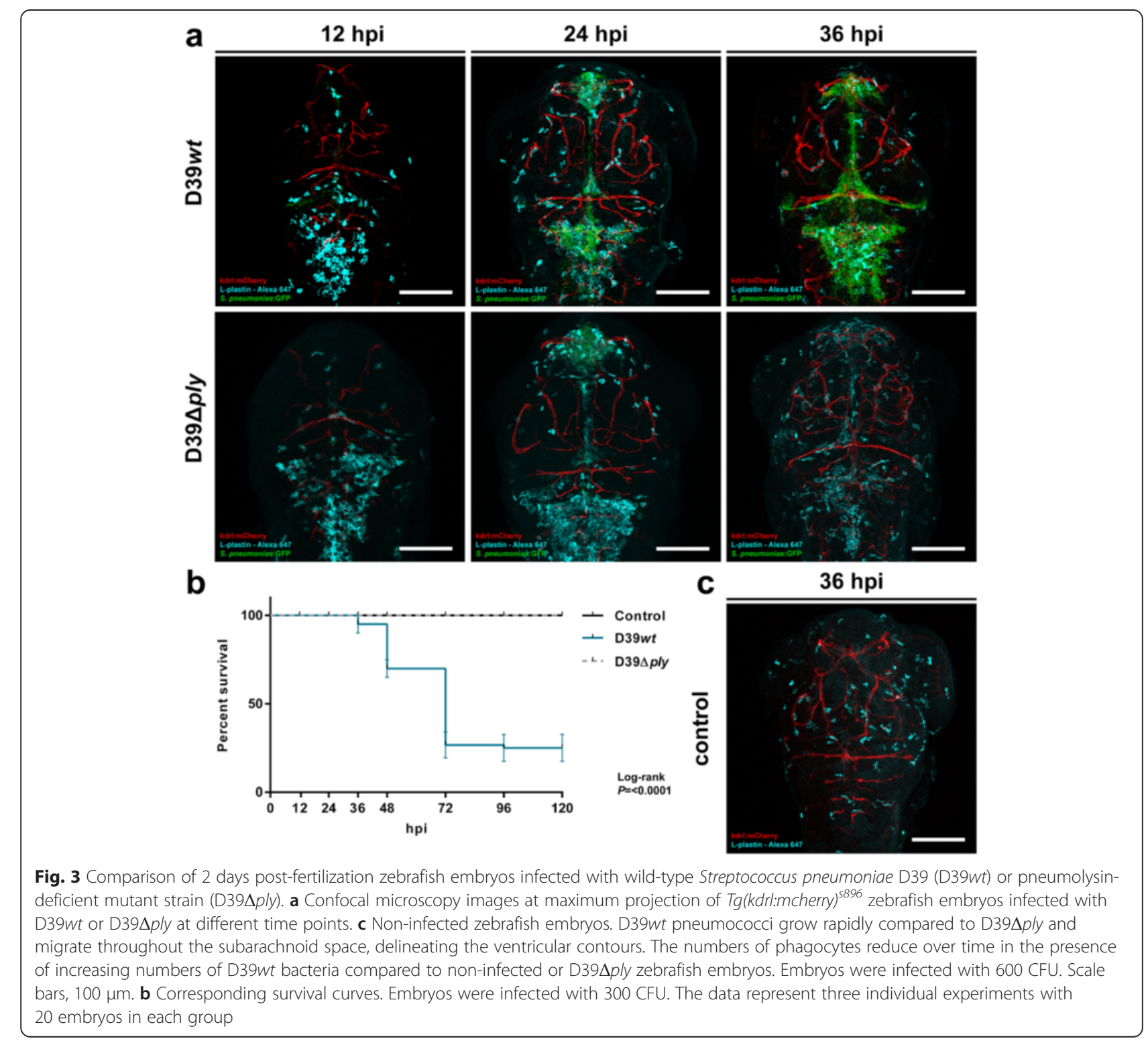




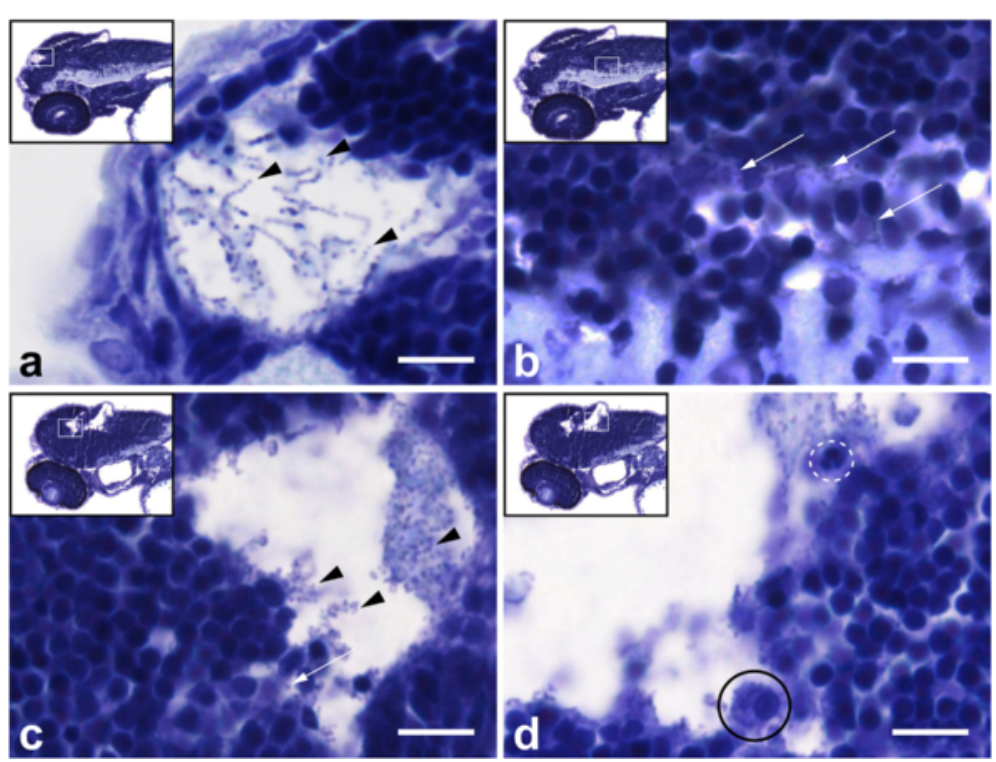

Fig. 4 Histopathological analysis of Streptococcus pneumoniae-infected zebrafish embryos via the hindbrain ventricle at 2 days post fertilization. a, b Sagittal section of the head region showing bacteria (arrow heads) in $\mathbf{a}$ the subarachnoid space and $\mathbf{b}$ brain parenchyma at $12 \mathrm{~h}$ post injection (hpi). c, d Sagittal section at 24 hpi showing increased amount of bacteria in the subarachnoid space (arrow heads) and disruption of the ventricular lining with bacterial infiltration (arrow) in $\mathbf{c}$ and a neutrophil (dotted circle) and a phagocytosing macrophage (circle) in $\mathbf{d}$. Scale bars, $10 \mu \mathrm{m}$

meningitis model, we injected the mutant bacteria in the hindbrain ventricle with equal doses as the wild-type bacteria (Fig. 1a). Infection with S. pneumoniae D39 $\Delta$ ply in the hindbrain ventricle showed attenuated growth and migration through the subarachnoid space and brain as compared to the wild-type D39 strain (Fig. 3a). The mean survival percentage 5 dpi was significantly higher compared to zebrafish embryos infected with the wildtype strain (100 vs $25 \%, P=<0.0001$ ) (Fig. 3b). To visualize the differences in infection dynamics between the pneumolysin-deficient mutant and the wild-type strain, $T g(k d r l: m C h e r r y)^{s 896}$, zebrafish embryos were infected with the green fluorescent HlpA-GFP S. pneumoniae D39 4 ply strain and phagocytes were stained with anti-Lplastin. At early stages of infection, bacteria were observed in the subarachnoid space with large numbers of phagocytes at the site of infection. The number of bacteria reduced over time in the presence of increasing numbers of phagocytes (predominantly macrophages) (Fig. 3a and Additional file 2: Figure S2). At 36 hpi, no bacteria were found in the subarachnoid space, while phagocytes continued to delineate its contours. This pattern was distinct from that in non-infected zebrafish embryos, where phagocytes appeared scattered throughout the whole brain
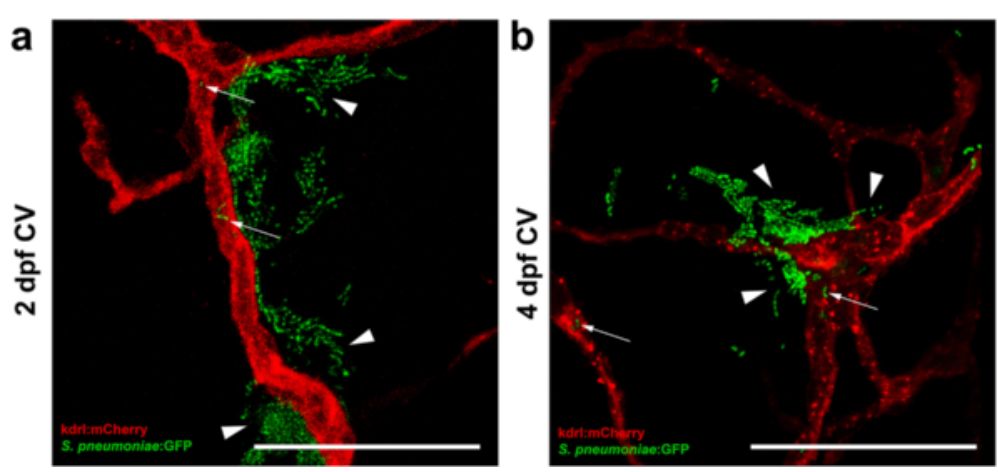

Fig. 5 Pneumococci leave the blood vessels after systemic infection. a, b Confocal microscopy images at maximum projection of $\mathrm{Tg}(\mathrm{kdrl}: \mathrm{mcherry})^{5896}$ zebrafish embryos injected in the caudal vein (CV) a before formation of the blood-brain barrier (BBB) at 2 days post fertilization (dpf) or $\mathbf{b}$ after the formation of the BBB at $4 \mathrm{dpf}$. Bacteria were localized inside (arrows) and outside (arrow heads) the blood vessels. All embryos were infected with $400 \mathrm{CFU}$ and imaged at $24 \mathrm{~h}$ post injection. Scale bars, $50 \mu \mathrm{m}$ 


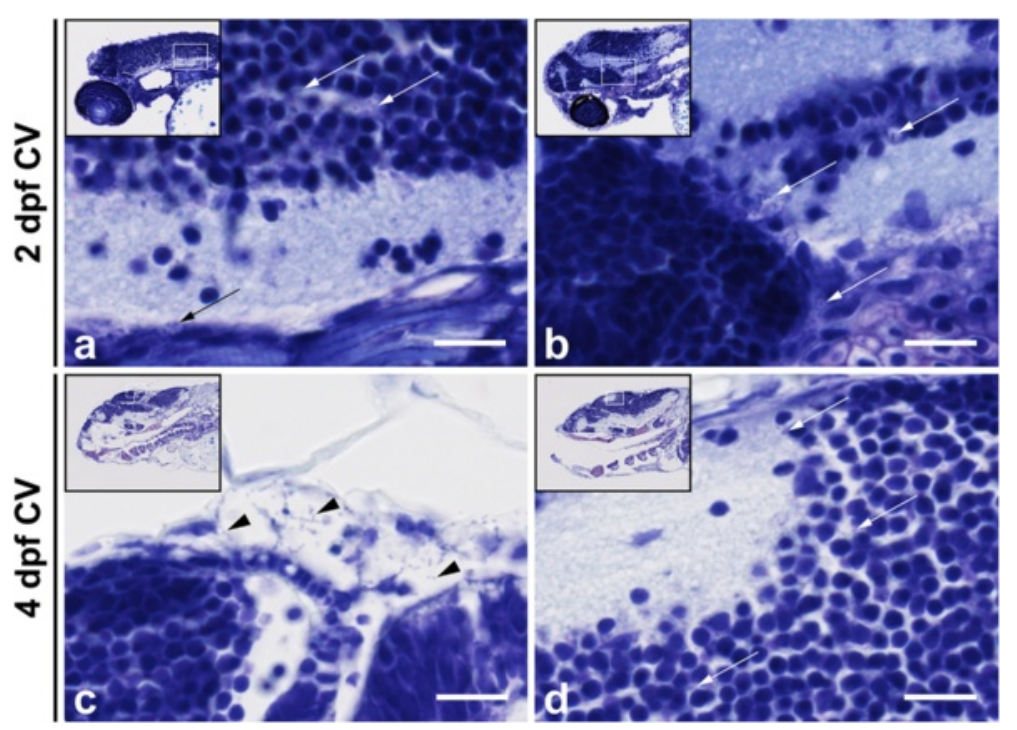

Fig. 6 Histopathological analysis of Streptococcus pneumoniae-infected zebrafish embryos via the caudal vein at 2 days post - fertilization. a, b Caudal vein injection at 2 days post - fertilization (dpf). Sagittal section of the head region showing the bacteria (arrows) in the brain parenchyma at $\mathbf{a} 12 \mathrm{~h}$ post injection (hpi) and at b $24 \mathrm{hpi}$. c, d Caudal vein-injected zebrafish embryos at $4 \mathrm{dpf}$. c Sagittal section at 24 hpi showing bacteria (arrows) in the meningeal space and in $\mathbf{d}$ the brain parenchyma. Scale bars, $10 \mu \mathrm{m}$

at this time point (Fig. 3c). These findings were consistent with the survival data, showing attenuated virulence of $S$. pneumoniae D394ply compared to wild-type S. pneumoniae D39 and also seem to confirm that reduction of phagocytes in wild-type infections at later time points is probably due to pneumolytic activity.

\section{Infection before and after formation of the blood-brain barrier}

The blood-brain barrier (BBB) forms on day 3 post fertilization and continues to mature till $10 \mathrm{dpf}$ in zebrafish [43-45]. To examine whether the blood-brain barrier influences the migration of bacteria to the central nervous system, we injected HlpA-GFP wild-type S. pneumoniae D39 in the caudal vein of $4 \mathrm{dpf} T g(k d r l: m \text { Cherry })^{s 896}$ zebrafish embryos (after formation of $\mathrm{BBB}$ ) and compared this with $2 \mathrm{dpf}$ infected zebrafish embryos (before formation of BBB). In addition, we performed histopathological analysis with Nissl staining to determine the spreading and localization of bacteria in both 2 and $4 \mathrm{dpf}$ zebrafish embryos. After bloodstream injection, pneumococci were seen migrating out of the blood vessels and into the central nervous system after 24 hpi in both 2 and $4 \mathrm{dpf}$ zebrafish embryos (Fig. 5a, b). However, histopathological analysis showed bacterial infiltration of brain parenchyma at $12 \mathrm{hpi}$ in $2 \mathrm{dpf}$ zebrafish embryos and at $24 \mathrm{hpi}$ in $4 \mathrm{dpf}$ zebrafish embryos (Fig. 6). Interestingly, clogging of the blood vessels by pneumococci was commonly observed in caudal vein-infected zebrafish embryos and bacteria were frequently found outside of these vessels (Fig. 7). Together, these data indicate that migration to the subarachnoid space and brain tissue occurs in zebrafish before and after the formation of the blood-brain barrier, be it that after the formation of the blood-brain barrier this migration occurs at a later time point.

\section{Initial innate immune response during pneumococcal meningitis in zebrafish embryos consists mainly of neutrophils}

To study the dynamics of the innate immune response against S. pneumoniae, we injected $\operatorname{Tg}(m p x: G F P)^{i 114} / T g$ (mpeg1:mCherry) ${ }^{g l 23}$ zebrafish embryos in the hindbrain ventricle with wild-type $S$. pneumoniae and performed time-lapse fluorescence imaging (Additional file 3: Movie $\mathrm{S} 1$ ). From as early as $15 \mathrm{~min}$ after injection, neutrophils migrated into the subarachnoid space. While neutrophils accumulated over time, no macrophages appeared to move towards the infection site during this early stage of infection, despite their presence in regions below the subarachnoid space (Fig. 8b, c). Zebrafish embryos injected with PBS showed no migration of neutrophils or macrophages (Fig. 8a). This shows that neutrophils are the primary immune cells that are migrating towards loci of pneumococcal infection in the brain tissue.

\section{Discussion}

We developed and characterized a zebrafish embryo infection model of pneumococcal meningitis allowing real-time investigation of early host-microbe interaction. Meningitis developed both after systemic injection in the caudal vein or local injection in the hindbrain ventricle. Infection with a pneumolysin-deficient pneumococcal 

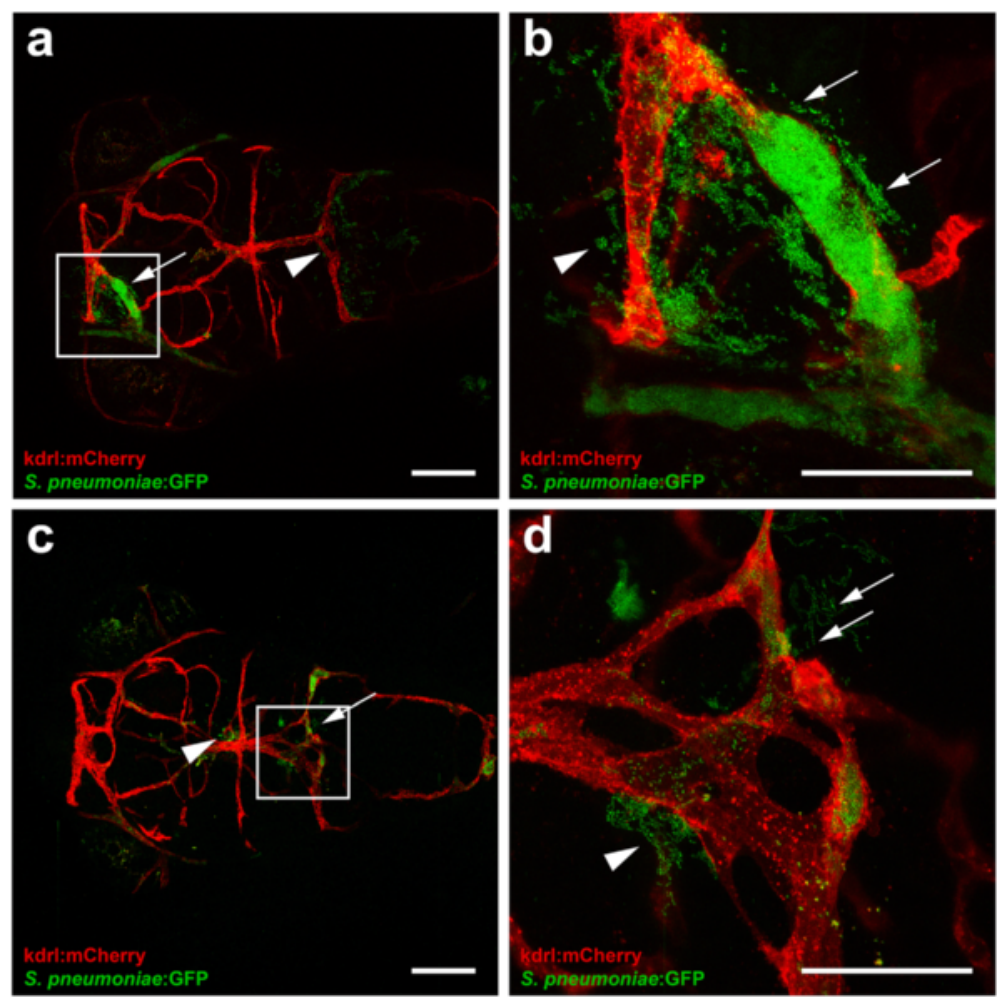

Fig. 7 Clogging of the blood vessels by Streptococcus pneumoniae after systemic infection. a-d Confocal microscopy images at maximum projection of $\mathrm{Tg}\left(\mathrm{kdrl}: \mathrm{mcherry}^{5896}\right.$ zebrafish embryos at 4 days post- fertilization injected in the caudal vein. a, $\mathbf{c}$ Bacteria were localized inside and outside of the blood vessels with (arrows) and without clogging (arrow heads). Scale bars, $100 \mu \mathrm{m}$. b, d An enlarged view of a and c, respectively, with clogging of a blood vessel highlighted. All embryos were infected with $600 \mathrm{CFU}$ and imaged at $24 \mathrm{~h}$ post injection. Scale bars, $50 \mu \mathrm{m}$

mutant strain in the hindbrain ventricle showed attenuated growth in the subarachnoid space and attenuated migration through the brain as compared to the wild-type strain. In the wild-type strain infection, the number of phagocytes reduced quickly after initial accumulation at the site of infection, in contrast to the pneumolysin-deficient mutant infection, where numbers of phagocytic cells kept accumulating in the subarachnoid space. This observation suggested that cytolytic activity, mediated by pneumolysin, may be responsible for the reduction of phagocytic cells. Time-lapse imaging showed that the initial zebrafish phagocytic innate immune response in pneumococcal meningitis mainly consisted of neutrophils, comparable to the human situation [4].

Zebrafish embryos and larvae are becoming increasingly popular to model infectious diseases, including infections of the central nervous system [19, 21, 26, 29, 46, 47]. The optical clarity of zebrafish embryos and larvae in conjunction with transgenic zebrafish lines, fluorescently labelled bacteria and immunohistochemistry provide unique possibilities for real-time in vivo imaging of infection dynamics in the central nervous system in detail. This approach has led to the successful modelling of tuberculous meningitis and Streptococcus agalactiae meningitis in zebrafish embryos and better understanding of the molecular and cellular pathogenesis of the disease [29, 46]. Given the potential of this model to study central nervous system infections, it is therefore recommended and desirable to further adapt the zebrafish embryo to study other forms of bacterial meningitis. Since it has been demonstrated that zebrafish are susceptible to Listeria monocytogenes, Streptococcus suis, Streptococcus iniae and Escherichia coli infection, zebrafish meningitis models should be developed for these bacteria and opportunities for other meningitis-causing pathogens explored [48-51].

Injection of wild-type $S$. pneumoniae in the hindbrain ventricle or caudal vein caused a fulminant dose-dependent infection in zebrafish embryos. Caudal vein injection was associated with more severe disease outcome as compared to hindbrain ventricle injection, suggesting tissue-specific susceptibility to pneumococcal infection. A similar trend was observed in Staphylococcus aureus-infected zebrafish embryos, where infection of the hindbrain ventricle elicited a stronger immunological response as compared to systemic infection [47]. A recent study showed that the innate immune response to pneumococcal infection in zebrafish 


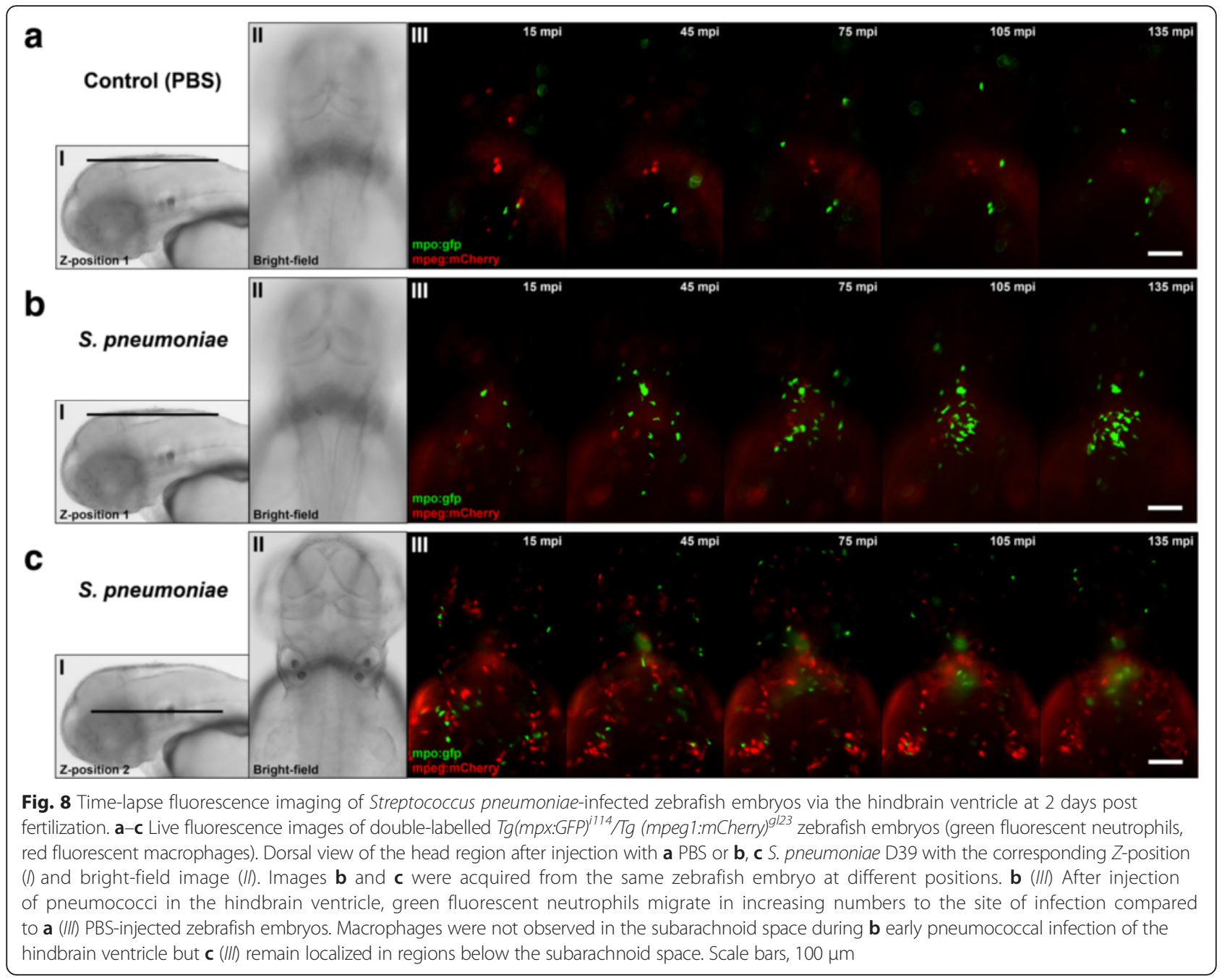

embryos is highly dependent on phagocytic cells (macrophages and neutrophils) [30]. The difference in phagocyte recruitment upon injection via different routes may explain the difference in survival that we observed. The association between lack of leukocyte response and adverse outcome has been described before: a low cerebrospinal fluid whitecell count was associated with an adverse outcome in patients with pneumococcal meningitis [5]. Studies in rats showed a relation between large numbers of bacteria in the cerebrospinal fluid load, lack of response of cerebrospinal fluid leukocytes and intracranial complications [52].

Pneumolysin is a crucial multifunctional virulence factor, which is best known for its cholesteroldependent cytolytic activity of host cells, but also induces activation of the complement pathway, activation of pro-inflammatory immune cell reactions and induction of apoptosis [53]. The role of pneumolysin in the pathogenesis of pneumococcal meningitis has been controversial [54]. Recent studies, however, show that pneumolysin plays an important role in the pathogenesis of pneumococcal meningitis and that unfavourable outcome in meningitis is driven by a combination of bacteria and host-derived toxins [4, 54-57]. In line with these studies, the pneumolysin-deficient mutant was attenuated as compared to the wild-type strain after hindbrain ventricle injection; real-time imaging showed the differences in innate immune response upon infection with these strains. After infection of the hindbrain ventricle with wild-type pneumococci, large numbers of phagocytes migrated to the site of infection. However, as the infection progressed, the numbers of phagocytes diminished over time in the presence of increasing numbers of bacteria. In contrast, after hindbrain ventricle infection with pneumolysin-deficient pneumococci, phagocytes remained present in large numbers while bacteria were cleared over time. These observations may be explained by a biological phenomenon called apoptosis-associated killing of bacteria. Macrophage apoptosis has been described as a 
mechanism for pneumococcal clearance when other killing mechanisms are exhausted and is initiated by lysosomal membrane permeabilization [58-60]. Induction of this mechanism by pneumococci requires opsonization and is correlated with the intracellular bacterial burden [59-61]. A recent study shows that pneumolysin is necessary for lysosomal membrane permeabilization and thus induction of macrophage apoptosis-associated killing of pneumococci [62]. In addition, in vitro studies show that infection using pneumolysin-deficient strains resulted in a significant reduction of macrophage apoptosis [59, 63]. Altogether, these data strongly suggest that the observed differences in host innate immune response between infection with wild-type and pneumolysindeficient pneumococci may be due to the ability and necessity to activate this macrophage apoptosisassociated killing mechanism.

Bacterial meningitis develops when bacteria enter and survive in the bloodstream, interact with the BBB and penetrate the central nervous system [4]. In pneumococcal meningitis, crossing of the $\mathrm{BBB}$ by $S$. pneumoniae is thought to occur by intracellular or intercellular translocation, although the exact mechanisms remain unclear [4]. The BBB is formed by endothelial cells with tight junctions, astrocytes and pericytes, and the main function is to protect the central nervous system from microorganisms and toxins that are circulating in the blood [64]. Previous studies showed that zebrafish have a functional BBB similar to that of mammals, and are therefore suitable for studying mechanisms involved in the disruption and penetration of the BBB [43-45]. A recent study by Kim et al. demonstrated that infection with $S$. agalactiae in zebrafish induces the Snail1 host transcription factor, which downregulates tight junctions, and disrupts the BBB [65]. In order to investigate whether the zebrafish embryo model can be used to study pneumococcal crossing of the BBB, we infected $T g(k d r l: m C h e r r y)^{s 896}$ zebrafish embryos that express red fluorescence in the blood vessels with green fluorescent pneumococci. Wild-type pneumococci injected in the caudal vein migrated out of the blood vessels and caused meningitis in zebrafish embryos before as well as after the formation of the BBB. Histopathological analysis confirmed these findings and showed bacteria in the subarachnoid space and brain parenchyma in both 2 and $4 \mathrm{dpf}$ zebrafish embryos infected systemically. This is in line with data from adult zebrafish, where intraperitoneal injection of pneumococci causes bacteraemia and subsequent meningitis [31]. These findings suggest that the zebrafish embryo model is suitable to elucidate the mechanism by which pneumococci cross the BBB in meningitis.

In our analysis, we also detected clogging of the blood vessels by pneumococci in the bloodstream-infected zebrafish embryos, with bacteria localized outside and in proximity to these affected vessels. In addition to the aforementioned mechanisms by which pneumococci can infiltrate the central nervous system, mechanical disruption of vascular endothelium by pneumococci could possibly be another mechanism by which pneumococci leave the bloodstream and invade the brain. Furthermore, clogging of the blood vessels may cause interruption of the blood flow and subsequent cerebral infarction in zebrafish embryos. In patients with pneumococcal meningitis, cerebral infarction has been described as a common complication [66-70]. Whereas the exact mechanism remains to be elucidated, previous studies show that severe infection can activate the coagulation pathway and diffuse intravasal coagulation may contribute to the pathogenesis of cerebral infarction $[69,71]$.

Although there are many advantages of the zebrafish as an infection model, there are also some limitations. First, most human pathogens are adapted to cause infection at $37{ }^{\circ} \mathrm{C}$, whereas the ideal temperature for zebrafish is around $28{ }^{\circ} \mathrm{C}$. The difference in temperature might influence the natural disease course of human pathogens in these animals. Translation from the zebrafish model to the human infectious disease might therefore not always be possible. Second, monoclonal antibodies directed to surface antigens of cells of the zebrafish immune system are scarce [21,72]. Finally, the immune cells of the adaptive immune response that have been assumed to play a role in the innate immune response to pneumococcal infection show a different pattern in zebrafish as compared to mice and human $[31,73]$. Moreover, there is evidence that zebrafish have a tissue-restricted expression of Tolllike receptors and the repertoire of components of the zebrafish innate immune system seems to be more diverse that in mice or humans [74, 75]. Despite these differences, the zebrafish embryo model has been proven very useful to study several human pathogens, e.g. Mycobacterium tuberculosis, and has provided important new insights in the pathogenesis of tuberculosis [76]. Also, our findings with respect to the pathogenesis of pneumococcal meningitis appear in line with those found in other animal models. Therefore, the zebrafish remains a powerful model organism to study infectious diseases.

\section{Conclusions}

In conclusion, we have developed and characterized a novel zebrafish embryo infection model to visualize and study pneumococcal meningitis infection dynamics in detail. This model shows the potential to extend our understanding of the interplay between bacterial virulence factors and host defence mechanisms in the pathogenesis of pneumococcal meningitis. In addition, our observations stress the need for targeting direct bacterial toxicity, for example, targeting pneumolysin, to prevent host-derived toxin-mediated brain damage and associated poor disease outcome in pneumococcal meningitis. 


\section{Additional files}

Additional file 1: Figure S1. Infection with green fluorescent wildtype HIpA-GFP Streptococcus pneumoniae D39 via the hindbrain ventricle can lead to systemic infection in zebrafish embryos. Fluorescence microscopy image at $36 \mathrm{~h}$ post injection. After infection of the embryos via the hindbrain ventricle, bacteria can disseminate into the bloodstream and cause a systemic infection. The embryo was infected at 2 days postfertilization with 300 CFU of Streptococcus pneumoniae D39 (HIpA-GFP).

Scale bar, 500 m. (JPG 505 kb)

Additional file 2: Figure S2. Macrophages are involved in the clearance of pneumolysin-deficient pneumococci (D39 $\Delta$ ply) in zebrafish embryos after infection via the hindbrain ventricle. Confocal microscopy images at maximum projection of double-labelled $\mathrm{Tg}(\mathrm{mpx}: \mathrm{GFP})^{i 174} / \mathrm{Tg}$ (mpeg 1:mCherry) gl/23 $^{2}$ zebrafish embryo (green fluorescent neutrophils (arrows), red fluorescent macrophages (arrowheads)) infected with 600 CFU Streptococcus pneumoniae D39 $\Delta$ ply in the hindbrain ventricle at 2 days post fertilization and imaged at $24 \mathrm{~h}$ post injection. Scale bar, 50 um. (JPG 902 kb)

Additional file 3: Movie S1. Time-lapse movie showing the initial innate immune response of Streptococcus pneumoniae-infected zebrafish embryos in the hindbrain ventricle. Dorsal view of Streptococcus pneumoniae-infected double-labelled Tg(mpx:GFP) ${ }^{i 714} / \mathrm{Tg}$ (mpeg 1:mCherry) ${ }^{g / 23}$ zebrafish embryo (green fluorescent neutrophils, red fluorescent macrophages) via the hindbrain ventricle at 2 days post fertilization. Fifteen minutes after the injection of pneumococci in the hindbrain ventricle, green fluorescent neutrophils migrate in increasing numbers to the site of infection, whereas macrophages were not observed in the hindbrain ventricle. Interval time between frames is $1 \mathrm{~min}$ for $2.5 \mathrm{~h}$. Frame rate is 7 frames per second. (MP4 $18374 \mathrm{~kb}$ )

\section{Abbreviations}

BBB, blood-brain barrier; BSA, bovine serum albumin; CFU, colony-forming units; Fc- $\gamma$, fc gamma; GFP, green fluorescent protein; HIpA, histone-like protein; hpf, hours post fertilization; hpi, hours post injection; kdrl, kinase insert domain receptor like; mpeg, macrophage expressed gene; mpx, myeloperoxidase; NGS, normal goat serum; PBS, phosphate-buffered saline; PBTx, Triton X-100 in phosphate-buffered saline; ply, pneumolysin; PspA, pneumococcal surface protein A; PTU, 1-phenyl 2-thiourea; sfGFP, superfolder green fluorescent protein; Tg, transgenic

\section{Acknowledgements}

The authors would like to thank Gunny van den Brink-Stempvoort, Lisanne van Leeuwen, Ben Nelemans, Manuel Schmitz, Wim Schouten and Theo Verboom for technical assistance. The anti-L-plastin antibody was a kind gift from Professor Paul Martin (Bristol University, UK)

\section{Funding}

MCB is supported by a grant from the Netherlands Organization for Health Research and Development (ZonMw; NWO-Veni grant 2012 [916.13.078]). DvdB is supported by grants from the Netherlands Organization for Health Research and Development (ZonMw; NWO-Vidi grant 2010 [016.116.358]) and the European Research Council (ERC Starting Grant 281156).

\section{Availability of data and materials}

The datasets supporting the conclusions of this article are included within the article (and its additional files).

\section{Authors' contributions}

KKJ and JE-L performed the experiments. KKJ, AvdS, WB, MCB, AvdE, DvdB and $C V-G$ initiated the project and designed the experiments. J-WV provided critical materials and critical discussion. KKJ, CV-G and DvdB wrote the manuscript with contributions from all co-authors. All authors discussed the results and commented on the manuscript. All authors read and approved the final manuscript.

\section{Competing interests}

The authors declare that they have no competing interests.

\section{Ethics approval and consent to participate}

All procedures involving zebrafish embryos were according to local animal welfare regulations. Consent to participate is not applicable.

\section{Author details}

${ }^{1}$ Department of Medical Microbiology and Infection Control, VU University Medical Center, De Boelelaan 1108, 1081 HZ Amsterdam, The Netherlands. ${ }^{2}$ Department of Neurology, Center of Infection and Immunity Amsterdam (CINIMA), Academic Medical Center, University of Amsterdam, Meibergdreef 9, 1105 AZ Amsterdam, The Netherlands. ${ }^{3}$ Department of Medical Microbiology, Center of Infection and Immunity Amsterdam (CINIMA), Academic Medical Center, University of Amsterdam, Meibergdreef 9, 1105 AZ Amsterdam, The Netherlands. ${ }^{4}$ The Netherlands Reference Laboratory for Bacterial Meningitis, Academic Medical Center, University of Amsterdam, Meibergdreef 9, 1105 AZ Amsterdam, The Netherlands. ${ }^{5}$ Molecular Genetics Group, Groningen Biomolecular Sciences and Biotechnology Institute, Centre for Synthetic Biology, University of Groningen, Nijenborgh 7, 9747 AG Groningen, The Netherlands. ${ }^{6}$ Department of Medical Microbiology and Infection Control, VU University Medical Center, P.O. Box 7057, 1007 MB Amsterdam, The Netherlands.

Received: 21 April 2016 Accepted: 8 July 2016

Published online: 19 August 2016

\section{References}

1. Brouwer MC, Tunkel AR, van de Beek D. Epidemiology, diagnosis, and antimicrobial treatment of acute bacterial meningitis. Clin Microbiol Rev. 2010;23:467-92.

2. O'Brien KL, Wolfson LJ, Watt JP, Henkle E, Deloria-Knoll M, McCall N, Lee E, Mulholland K, Levine OS, Cherian T, et al. Burden of disease caused by Streptococcus pneumoniae in children younger than 5 years: global estimates. Lancet. 2009;374:893-902.

3. McIntyre PB, O'Brien $\mathrm{KL}$, Greenwood B, van de Beek $\mathrm{D}$. Effect of vaccines on bacterial meningitis worldwide. Lancet. 2012;380:1703-11.

4. Mook-Kanamori BB, Geldhoff M, van der Poll T, van de Beek D. Pathogenesis and pathophysiology of pneumococcal meningitis. Clin Microbiol Rev. 2011;24:557-91.

5. van de Beek D, de Gans J, Spanjaard L, Weisfelt M, Reitsma JB, Vermeulen M. Clinical features and prognostic factors in adults with bacterial meningitis. N Engl J Med. 2004;351:1849-59.

6. van de Beek D, Brouwer MC, Thwaites GE, Tunkel AR. Advances in treatment of bacterial meningitis. Lancet. 2012;380:1693-702.

7. Hoogman M, van de Beek D, Weisfelt M, de Gans J, Schmand B. Cognitive outcome in adults after bacterial meningitis. J Neurol Neurosurg Psychiatry. 2007;78:1092-6.

8. Brouwer MC, de Gans J, Heckenberg SG, Zwinderman AH, van der Poll T, van de Beek D. Host genetic susceptibility to pneumococcal and meningococcal disease: a systematic review and meta-analysis. Lancet Infect Dis. 2009;9:31-44

9. Piet JR, Geldhoff M, van Schaik BD, Brouwer MC, Valls Seron M, Jakobs ME, Schipper K, Pannekoek Y, Zwinderman AH, van der Poll T, et al. Streptococcus pneumoniae arginine synthesis genes promote growth and virulence in pneumococcal meningitis. J Infect Dis. 2014;209:1781-91.

10. Kadioglu A, Weiser JN, Paton JC, Andrew PW. The role of Streptococcus pneumoniae virulence factors in host respiratory colonization and disease. Nat Rev Microbiol. 2008;6:288-301.

11. Mitchell AM, Mitchell TJ. Streptococcus pneumoniae: virulence factors and variation. Clin Microbiol Infect. 2010;16:411-8.

12. Weinberger DM, Malley $R$, Lipsitch M. Serotype replacement in disease after pneumococcal vaccination. Lancet. 2011;378:1962-73.

13. Hyams C, Camberlein E, Cohen JM, Bax K, Brown JS. The Streptococcus pneumoniae capsule inhibits complement activity and neutrophil phagocytosis by multiple mechanisms. Infect Immun. 2010;78:704-15.

14. Donati C, Hiller NL, Tettelin H, Muzzi A, Croucher NJ, Angiuoli SV, Oggioni M, Dunning Hotopp JC, Hu FZ, Riley DR, et al. Structure and dynamics of the pan-genome of Streptococcus pneumoniae and closely related species. Genome Biol. 2010;11:R107.

15. Croucher NJ, Mitchell AM, Gould KA, Inverarity D, Barquist L, Feltwell T, Fookes MC, Harris SR, Dordel J, Salter SJ, et al. Dominant role of nucleotide substitution in the diversification of serotype 3 pneumococci over decades and during a single infection. PLoS Genet. 2013;9:e1003868. 
16. Gerber J, Raivich G, Wellmer A, Noeske C, Kunst T, Werner A, Bruck W, Nau R. A mouse model of Streptococcus pneumoniae meningitis mimicking several features of human disease. Acta Neuropathol. 2001;101:499-508.

17. Chiavolini D, Pozzi G, Ricci S. Animal models of Streptococcus pneumoniae disease. Clin Microbiol Rev. 2008;21:666-85.

18. Mook-Kanamori B, Geldhoff M, Troost D, van der Poll T, van de Beek D. Characterization of a pneumococcal meningitis mouse model. BMC Infect Dis. 2012;12:71.

19. Meeker ND, Trede NS. Immunology and zebrafish: spawning new models of human disease. Dev Comp Immunol. 2008:32:745-57.

20. Torraca V, Masud S, Spaink HP, Meijer AH. Macrophage-pathogen interactions in infectious diseases: new therapeutic insights from the zebrafish host model. Dis Model Mech. 2014;7:785-97.

21. van der Sar AM, Appelmelk BJ, Vandenbroucke-Grauls CM, Bitter W. A star with stripes: zebrafish as an infection model. Trends Microbiol. 2004:12:451-7.

22. Meijer AH, Spaink HP. Host-pathogen interactions made transparent with the zebrafish model. Curr Drug Targets. 2011;12:1000-17.

23. Lam SH, Chua HL, Gong Z, Lam TJ, Sin YM. Development and maturation of the immune system in zebrafish, Danio rerio: a gene expression profiling, in situ hybridization and immunological study. Dev Comp Immunol. 2004;28:9-28.

24. Renshaw SA, Trede NS. A model 450 million years in the making: zebrafish and vertebrate immunity. Dis Model Mech. 2012:5:38-47.

25. Tobin DM, May RC, Wheeler RT. Zebrafish: a see-through host and a fluorescent toolbox to probe host-pathogen interaction. PLoS Pathog. 2012;8:e1002349.

26. Nasevicius A, Ekker SC. The zebrafish as a novel system for functional genomics and therapeutic development applications. Curr Opin Mol Ther. 2001;3:224-8.

27. Bowman TV, Zon LI. Swimming into the future of drug discovery: in vivo chemical screens in zebrafish. ACS Chem Biol. 2010;5:159-61.

28. Stoop EJ, Schipper T, Rosendahl Huber SK, Nezhinsky AE, Verbeek FJ, Gurcha SS, Besra GS, Vandenbroucke-Grauls CM, Bitter W, van der Sar AM. Zebrafish embryo screen for mycobacterial genes involved in the initiation of granuloma formation reveals a newly identified ESX-1 component. Dis Model Mech. 2011:4:526-36.

29. van Leeuwen LM, van der Kuip M, Youssef SA, de Bruin A, Bitter W, van Furth AM, van der Sar AM. Modeling tuberculous meningitis in zebrafish using Mycobacterium marinum. Dis Model Mech. 2014;7:1111-22.

30. Rounioja S, Saralahti A, Rantala L, Parikka M, Henriques-Normark B, Silvennoinen $\mathrm{O}$, Ramet M. Defense of zebrafish embryos against Streptococcus pneumoniae infection is dependent on the phagocytic activity of leukocytes. Dev Comp Immunol. 2012;36:342-8.

31. Saralahti A, Piippo H, Parikka M, Henriques-Normark B, Ramet M, Rounioja S. Adult zebrafish model for pneumococcal pathogenesis. Dev Comp Immunol. 2014;42:345-53.

32. Kjos M, Aprianto R, Fernandes VE, Andrew PW, van Strijp JA, Nijland R, Veening JW. Bright fluorescent Streptococcus pneumoniae for live-cell imaging of host-pathogen interactions. J Bacteriol. 2015;197:807-18.

33. Avery OT, Macleod CM, McCarty M. Studies on the chemical nature of the substance inducing transformation of pneumococcal types: induction of transformation by a desoxyribonucleic acid fraction isolated from pneumococcus type lii. J Exp Med. 1944;79:137-58,

34. Berry AM, Yother J, Briles DE, Hansman D, Paton JC. Reduced virulence of a defined pneumolysin-negative mutant of Streptococcus pneumoniae. Infect Immun. 1989;57:2037-42.

35. Chi NC, Shaw RM, De Val S, Kang G, Jan LY, Black BL, Stainier DY. Foxn4 directly regulates tbx $2 b$ expression and atrioventricular canal formation. Genes Dev. 2008;22:734-9.

36. Ellett F, Pase L, Hayman JW, Andrianopoulos A, Lieschke GJ. mpeg1 promoter transgenes direct macrophage-lineage expression in zebrafish. Blood. 2011:117:e49-56.

37. Renshaw SA, Loynes CA, Trushell DM, Elworthy S, Ingham PW, Whyte MK. A transgenic zebrafish model of neutrophilic inflammation. Blood. 2006;108:3976-8.

38. White RM, Sessa A, Burke C, Bowman T, LeBlanc J, Ceol C, Bourque C, Dovey M, Goessling W, Burns CE, Zon LI. Transparent adult zebrafish as a tool for in vivo transplantation analysis. Cell Stem Cell. 2008;2:183-9.

39. Karlsson J, von Hofsten J, Olsson PE. Generating transparent zebrafish: a refined method to improve detection of gene expression during embryonic development. Mar Biotechnol (NY). 2001:3:522-7.
40. Benard EL, van der Sar AM, Ellett F, Lieschke GJ, Spaink HP, Meijer AH: Infection of zebrafish embryos with intracellular bacterial pathogens. J Vis Exp. 2012;61:e3781.

41. Bennett CM, Kanki JP, Rhodes J, Liu TX, Paw BH, Kieran MW, Langenau DM, Delahaye-Brown A, Zon LI, Fleming MD, Look AT. Myelopoiesis in the zebrafish, Danio rerio. Blood. 2001;98:643-51.

42. Herbomel $P$, Thisse B, Thisse $C$. Ontogeny and behaviour of early macrophages in the zebrafish embryo. Development. 1999;126:3735-45.

43. Fleming A, Diekmann $H$, Goldsmith P. Functional characterisation of the maturation of the blood-brain barrier in larval zebrafish. PLoS One. 2013;8:e77548.

44. Jeong JY, Kwon HB, Ahn JC, Kang D, Kwon SH, Park JA, Kim KW. Functional and developmental analysis of the blood-brain barrier in zebrafish. Brain Res Bull. 2008;75:619-28.

45. Xie J, Farage E, Sugimoto M, Anand-Apte B. A novel transgenic zebrafish model for blood-brain and blood-retinal barrier development. BMC Dev Biol. 2010;10:76

46. Kim BJ, Hancock BM, Del Cid N, Bermudez A, Traver D, Doran KS. Streptococcus agalactiae infection in zebrafish larvae. Microb Pathog. 2015;79:57-60.

47. Li YJ, Hu B. Establishment of multi-site infection model in zebrafish larvae for studying Staphylococcus aureus infectious disease. J Genet Genomics. 2012;39:521-34.

48. Levraud JP, Disson O, Kissa K, Bonne I, Cossart P, Herbomel P, Lecuit M. Real-time observation of listeria monocytogenes-phagocyte interactions in living zebrafish larvae. Infect Immun. 2009;77:3651-60.

49. Zaccaria E, Cao R, Wells JM, van Baarlen P. A zebrafish larval model to assess virulence of porcine Streptococcus suis strains. PLoS One. 2016;11:e0151623.

50. Harvie EA, Green JM, Neely MN, Huttenlocher A. Innate immune response to Streptococcus iniae infection in zebrafish larvae. Infect Immun. 2013;81:110-21

51. Wiles TJ, Bower JM, Redd MJ, Mulvey MA. Use of zebrafish to probe the divergent virulence potentials and toxin requirements of extraintestinal pathogenic Escherichia coli. PLoS Pathog. 2009;5:e1000697.

52. Tauber MG, Kennedy SL, Tureen JH, Lowenstein DH. Experimental pneumococcal meningitis causes central nervous system pathology without inducing the 72-kd heat shock protein. Am J Pathol. 1992;141:53-60.

53. Hirst RA, Kadioglu A, O'Callaghan C, Andrew PW. The role of pneumolysin in pneumococcal pneumonia and meningitis. Clin Exp Immunol. 2004;138:195-201.

54. Hirst RA, Gosai B, Rutman A, Guerin CJ, Nicotera P, Andrew PW, O'Callaghan C. Streptococcus pneumoniae deficient in pneumolysin or autolysin has reduced virulence in meningitis. J Infect Dis. 2008;197:744-51.

55. Reiss A, Braun JS, Jager K, Freyer D, Laube G, Buhrer C, Felderhoff-Muser U, Stadelmann C, Nizet V, Weber JR. Bacterial pore-forming cytolysins induce neuronal damage in a rat model of neonatal meningitis. J Infect Dis. 2011:203:393-400.

56. Braun JS, Sublett JE, Freyer D, Mitchell TJ, Cleveland JL, Tuomanen EI, Webe $J R$. Pneumococcal pneumolysin and $\mathrm{H}(2) \mathrm{O}(2)$ mediate brain cell apoptosis during meningitis. J Clin Invest. 2002;109:19-27.

57. Gerber J, Nau R. Mechanisms of injury in bacterial meningitis. Curr Opin Neurol. 2010;23:312-8

58. Bewley MA, Marriott HM, Tulone C, Francis SE, Mitchell TJ, Read RC, Chain B, Kroemer G, Whyte MK, Dockrell DH. A cardinal role for cathepsin d in co-ordinating the host-mediated apoptosis of macrophages and killing of pneumococci. PLoS Pathog. 2011;7:e1001262.

59. Dockrell DH, Lee M, Lynch DH, Read RC. Immune-mediated phagocytosis and killing of Streptococcus pneumoniae are associated with direct and bystander macrophage apoptosis. J Infect Dis. 2001;184:713-22.

60. Dockrell DH, Marriott HM, Prince LR, Ridger VC, Ince PG, Hellewell PG, Whyte MK. Alveolar macrophage apoptosis contributes to pneumococcal clearance in a resolving model of pulmonary infection. J Immunol. 2003;171:5380-8.

61. Ali F, Lee ME, lannelli F, Pozzi G, Mitchell TJ, Read RC, Dockrell DH. Streptococcus pneumoniae-associated human macrophage apoptosis after bacterial internalization via complement and Fcgamma receptors correlates with intracellular bacterial load. J Infect Dis. 2003:188:1119-31.

62. Bewley MA, Naughton M, Preston J, Mitchell A, Holmes A, Marriott HM, Read RC, Mitchell TJ, Whyte MK, Dockrell DH. Pneumolysin activates macrophage lysosomal membrane permeabilization and executes apoptosis by distinct mechanisms without membrane pore formation. MBio. 2014;5:e01710-01714 
63. Marriott HM, Ali F, Read RC, Mitchell TJ, Whyte MK, Dockrell DH. Nitric oxide levels regulate macrophage commitment to apoptosis or necrosis during pneumococcal infection. FASEB J. 2004;18:1126-8.

64. Kim KS. Mechanisms of microbial traversal of the blood-brain barrier. Nat Rev Microbiol. 2008;6:625-34.

65. Kim BJ, Hancock BM, Bermudez A, Del Cid N, Reyes E, van Sorge NM, Lauth X, Smurthwaite CA, Hilton BJ, Stotland A, et al. Bacterial induction of Snail1 contributes to blood-brain barrier disruption. J Clin Invest. 2015;125:2473-83.

66. Katchanov J, Heuschmann PU, Endres M, Weber JR. Cerebral infarction in bacterial meningitis: predictive factors and outcome. J Neurol. 2010;257:716-20.

67. Pfister HW, Borasio GD, Dirnagl U, Bauer M, Einhaupl KM. Cerebrovascular complications of bacterial meningitis in adults. Neurology. 1992;42:1497-504.

68. Schut ES, Lucas MJ, Brouwer MC, Vergouwen MD, van der Ende A, van de Beek D. Cerebral infarction in adults with bacterial meningitis. Neurocrit Care. 2012:16:421-7.

69. Vergouwen MD, Schut ES, Troost D, van de Beek D. Diffuse cerebral intravascular coagulation and cerebral infarction in pneumococcal meningitis. Neurocrit Care. 2010;13:217-27.

70. Weisfelt M, van de Beek D, Spanjaard L, Reitsma JB, de Gans J. Clinical features, complications, and outcome in adults with pneumococcal meningitis: a prospective case series. Lancet Neurol. 2006;5:123-9.

71. Levi M, van der Poll T, Buller HR. Bidirectional relation between inflammation and coagulation. Circulation. 2004;109:2698-704.

72. Lieschke GJ, Currie PD. Animal models of human disease: zebrafish swim into view. Nat Rev Genet. 2007:8:353-67.

73. Kadioglu A, Andrew PW. The innate immune response to pneumococcal lung infection: the untold story. Trends Immunol. 2004;25:143-9.

74. Saralahti A, Ramet M. Zebrafish and Streptococcal infections. Scand J Immunol. 2015;82:174-83.

75. Trede NS, Langenau DM, Traver D, Look AT, Zon LI. The use of zebrafish to understand immunity. Immunity. 2004;20:367-79.

76. van Leeuwen $L M$, van der Sar AM, Bitter W. Animal models of tuberculosis: zebrafish. Cold Spring Harb Perspect Med. 2015;5:a018580.

\section{Submit your next manuscript to BioMed Central and we will help you at every step:}

- We accept pre-submission inquiries

- Our selector tool helps you to find the most relevant journal

- We provide round the clock customer support

- Convenient online submission

- Thorough peer review

- Inclusion in PubMed and all major indexing services

- Maximum visibility for your research

Submit your manuscript at www.biomedcentral.com/submit

C Biomed Central 